\section{Analysis of mortality from diarrheic diseases in under-five children in Brazilian cities with more than 150,000 inhabitants}

\author{
Mortalidade por doenças diarréicas em menores \\ de cinco anos, em municípios brasileiros \\ com mais de 150 mil habitantes
}

\author{
${ }_{1}^{1}$ Universidade Estácio de Sá, \\ Rio de Janeiro, Brasil \\ 2 Instituto de Medicina \\ Social, Universidade do \\ Estado do Rio de Janeiro, \\ Rio de Janeiro, Brasil. \\ Correspondence \\ J. V. Sergio \\ Universidade Estácio de Sá. \\ Rua Fonte da Saudade 293, \\ apto. 702, Rio de Janeiro, $R J$ \\ 22471-210, Brasil. \\ juracisergio@uol.com.br
}

\begin{abstract}
This study analyzes mortality from infectious diarrheic diseases in children under 5 years of age in Brazilian municipalities with more than 150,000 inhabitants, excluding State capitals. The annual mortality rates by municipality from 1990 to 2000 were analyzed using a multilevel model, with years as first level units nested in municipalities as second level units. The dependent variable was the yearly mortality rate by municipality, on the log scale. Polynomial time trends and indicator variables to account for differences in geographic regions were used in the modeling. Time trends were centered on 1995, so they could be modeled differently before and after 1995. From 1990 to 1995 there was a sharp decrease in mortality rates by diarrheic diseases in most Brazilian municipalities, while from 1995 to 2000 the decrease was more heterogeneous. In 1995 the North and Northeast of Brazil had higher mortality rates than the Southeast, and the differences were statistically significant. Most importantly, the study concludes that there was an important difference in the pattern of mortality rate decreases over time, comparing the country's five geographic regions.
\end{abstract}

Diarrhea; Infant Mortality; Child Welfare
Juraci Vieira Sergio 1

Antônio Carlos Ponce de Leon 2

\section{Introduction}

Diarrheic diseases are an important cause of child morbidity and mortality in developing countries, with an estimated 1.3 billion episodes and 4 million deaths per year in children under five years of age. These children have an average of $3.3 \mathrm{epi}-$ sodes per year, but in some areas this figure exceeds nine episodes. In places where episodes are frequent, children can spend more than $15 \%$ of their days with diarrhea. Approximately $80 \%$ of deaths due to diarrhea occur in the first two years of life. The principal cause of death from acute diarrhea is dehydration, as the result of fluid and electrolyte loss. Other important causes of death are dysentery and malnutrition 1 .

Diarrheic diseases also have a major impact on the economy of developing countries. In many countries, children with diarrhea occupy more than one-third of the pediatric hospital beds. These patients are frequently treated with expensive intravenous solutions and ineffective drugs. Although diarrheic diseases are less harmful in adults than in children, they can affect the economy of these countries by undermining the health of the workforce 1 .

Epidemiological studies frequently define diarrhea as the occurrence of three or more loose or watery stools in 24 hours. Three clinical diarrheic syndromes are well defined, each with a specific pathogenesis, and requiring different treatments: 
acute watery diarrhea, dysentery, and persistent diarrhea 1 .

The infectious agents that cause diarrhea are usually spread by the fecal-oral route, including the ingestion of water or food contaminated with feces, person-to-person transmission, and direct contact with feces. Examples of behaviors that contribute to the spread of pathogens are: preparing food with dirty hands that have touched the soil during defecation and have not been washed, and allowing children to crawl or play in areas contaminated with animal or human feces 1 .

Certain factors increase the risk of acquiring or dying from infectious diarrheic diseases. Behavioral factors include 1 : interruption of exclusive breastfeeding before six months of life; failure to continue breastfeeding until completing at least one year of life; use of baby bottles, which are easily contaminated with fecal bacteria and are difficult to clean; storing food at room temperature; failure to wash hands before handling food; and failure to dispose of feces (including those of children) hygienically. Host-related factors include: malnutrition; current or recent measles; immunodeficiency or immunodepression; and age, especially 6 to 11 months.

Infectious diarrheic diseases display distinct seasonal patterns in different geographic areas. In temperate climates, bacterial diarrhea tends to occur more frequently in the summer, while viral diarrhea, particularly when caused by rotavirus, reaches its peak during the winter. In tropical areas, rotavirus diarrhea occurs throughout the year, increasing in frequency during the cold and dry months, with transmission by water and food as important routes 2 .

The main microorganisms frequently associated with diarrhea in children are: rotavirus, enterotoxigenic Escherichia coli, Shigella, Campylobacter jejuni, and Cryptosporidium. Importantly, two enteric pathogens, Vibrio cholerae and type1 Shigella dysenteriae, cause epidemics with high morbidity in all age groups. Since 1961, cholera caused by the El Tor biotype of Vibrio cholerae 01 spread in countries of Asia, the Eastern Mediterranean, Africa, some areas of Europe, and the Americas 1. In Brazil, cholera accounted for the increase in mortality from infectious diarrheic diseases in the early 1990s 3 .

As observed in other countries, in Brazil the mortality from these diseases also reaches higher levels in the less developed regions (Table 1).

Regional inequalities are also evident when analyzing the municipal Human Development Index (HDI-M). Considering the 100 municipalities (counties) with the highest HDI-M in Brazil, only four are located outside the South and Southeast regions: Brasilia, Fernando de Noronha (Pernambuco), Campos de Júlio (Mato Grosso), and Chapadão do Céu (Goiás). The first two have quite specific characteristics, and the other two are located on successful agricultural frontiers 4 .

The current study focused on the annual mortality rates from infectious diarrheic diseases in children under five years of age in 122 municipalities with more than 150 thousand inhabitants each, grouped according to the country's five geographic regions, from 1990 to 2000.

In epidemiological studies, when measurements, counts, or simple verification of the occurrence of an event are performed repeatedly in a sample of individuals over time, a hierarchical data structure naturally emerges. In this structure, the time measurements constitute the first level and the individuals the second level 5 . In this study design, intra-individual measurements are characterized by auto-correlation, thus lacking the independence between observations that simpler statistical models consider as a general premise. Thus, the effect of auto-correlation on estimates of parameters in statistical models must

Table 1

Mortality rate from infectious diarrhea in children under five years, according to Region of Brazil, 1990-2000.

\begin{tabular}{lcccccccccccccc}
\hline Region & 1990 & 1991 & 1992 & 1993 & 1994 & 1995 & 1996 & 1997 & 1998 & 1999 & 2000 & & & \\
\hline North & 0.00100 & 0.00078 & 0.00074 & 0.00076 & 0.00073 & 0.00068 & 0.00007 & 0.00006 & 0.00007 & 0.00005 & 0.00005 \\
Northeast & 0.00091 & 0.00083 & 0.00082 & 0.00086 & 0.00077 & 0.00068 & 0.00010 & 0.00008 & 0.00011 & 0.00009 & 0.00006 \\
Southeast & 0.00076 & 0.00065 & 0.00065 & 0.00066 & 0.00065 & 0.00060 & 0.00004 & 0.00003 & 0.00003 & 0.00002 & 0.00002 \\
South & 0.00063 & 0.00057 & 0.00053 & 0.00054 & 0.00054 & 0.00050 & 0.00004 & 0.00003 & 0.00003 & 0.00003 & 0.00003 \\
Central-West & 0.00058 & 0.00057 & 0.00054 & 0.00055 & 0.00059 & 0.00058 & 0.00005 & 0.00004 & 0.00004 & 0.00003 & 0.00003 \\
Total & 0.00079 & 0.00070 & 0.00068 & 0.00070 & 0.00067 & 0.00061 & 0.00006 & 0.00005 & 0.00006 & 0.00005 & 0.00004
\end{tabular}

Source: Mortality Information System (SIM), Information Technology Department, Unified National Health System (DATASUS; http://www.datasus.gov.br). 
be corrected. The multilevel model contemplates data hierarchies and allows the auto-correlation structures to be taken into consideration and their effects to be corrected appropriately. In the current study, the mortality rates over time in the municipalities constitute the outcome variable, the years during the period studies are the firstlevel unit, and the municipalities are the secondlevel units.

The auto-correlation of these data can be explained by the characteristics of the diseases under study, i.e., the occurrence of one case of diarrhea can influence the occurrence of other cases, thus altering the probability of individuals presenting the disease. This phenomenon is a function of characteristics of individuals, but also of municipalities, e.g., access to clean drinking water and/or environmental sanitation, supply of health services, the population's educational level, etc. These indicators display continuous time trends, so it is natural for an auto-correlation structure to exist in the intra-municipal mortality rates.

Multilevel models are more adequate for analyzing data that display a hierarchical structure, since they are capable of correctly estimating the variances in the target associations, besides directly analyzing higher-level risk factors, including ecological factors. Longitudinal data, also known as repeat measurements, like those used in the current study, are possible to be analyzed by multilevel models, to the extent that they possess a hierarchical structure 6,7 .

This article is intended to contribute to the knowledge on mortality from infectious diarrheic diseases in Brazil. The data analysis will be based on four questions: (1) Do the mortality rates vary between municipalities?; (2) What is the time trend in the mortality rates in these municipalities?; (3) Do the regions explain the baseline mortality scenario for the period studied (1995)?; and (4) Do the geographic regions explain differences in rates between the municipalities?

\section{Methodology}

A total of 122 municipalities were selected for the current study: 3 from the North of Brazil, 20 from the Northeast, 71 from the Southeast, 24 from the South, and 5 from the Central-West. All the municipalities with more than 150 thousand inhabitants were included, based on the 2000 Population Census by the Brazilian Institute of Geography and Statistics, or National Census Bureau - IBGE (http://www.ibge.gov.br). In total, this group of municipalities represents $22 \%$ of Brazil's population. The State capitals were excluded due to the heterogeneity of their populations, with pockets of poverty in the midst of urban areas with higher purchasing power. In order to include the State capitals, it would have been necessary to divide them into smaller areas according to socioeconomic criteria and to analyze the data based on these territorial divisions. However, no secondary data are available based on these criteria, making this form of analysis unfeasible. Meanwhile, medium-sized Brazilian municipalities tend to be more homogeneous in their socioeconomic distribution. The new municipalities that were created by reapportionment during the study period had their mortality rates calculated starting with the year in which they were founded. For the years prior to their consolidation, they were tallied as blank in the database. The model chosen for the data analysis is able to deal with such missing information.

We chose to target the under-five population, since it displays higher vulnerability and accounts for more than $80 \%$ of the deaths from diarrhea 1 .

The analysis of trends in infectious diarrheic diseases was based on mortality data. These data are more reliable and comprehensive for working with what we refer to as secondary data ${ }^{8}$. Coverage for mortality data in urban areas reaches $100 \%$ 9. The mortality data were obtained from the Mortality Information System (SIM), from the Information Technology Department of the Unified National Health System - DATASUS (http:// www.datasus.gov.br). The study included deaths of children under five years of age according to the Ninth 10 and Tenth Revisions 11 of the International Classification of Diseases (ICD), with the following codes: (a) 001-009, from 1990 to 1995 (ICD-9) 10; (b) A00-A09, from 1996 to 2000 (ICD-10) 11.

Considering the 122 municipalities and the entire 11-year period, there were a total of 1,338 observations, and in 89 cases no deaths were recorded. There were four blank observations, related to municipalities that had still not been created.

The outcome variable in the analytical model will be the log of the mortality rates. To avoid numerical problems when calculating logs, 0.5 was added to the observations with zero deaths.

The analytical procedures used MLWinN version 1.2 (Centre for Multilevel Modelling, Bristol, UK). The analytical strategy was divided into four stages. In the first, the data were analyzed according to the "empty" model, i.e., without explanatory variables, only with the fixed effect of the intercept (overall mean) and its random effects on the two levels of the data hierarchy. Based on this model's fit, one obtains an estimate of the 
intraclass correlation coefficient (ICC), which measures the proportion of total variance due to differences in the mortality rates between municipalities.

The next stage was to analyze the behavior of the mortality rates over time. The time trends were described by a parametric spline function. This function is appropriate for modeling longitudinal measurements 12,13. During the modeling process, "nodes" are inserted that divide the study period into intervals. Next, polynomials are adjusted by intervals and interconnected at the nodes. The number of nodes and the polynomial's degree are chosen so as to provide adequate smoothing of the patterns observed in the data. For more details on this function, see Snijders \& Bosker 14. The current study opted for a single node at baseline (1995) and a cubic spline, which consists of a linear term, a quadratic, and two third-degree polynomials, one on each side of the node. Thus, the curves on each side of the node differ slightly in their specifications, thereby allowing modeling the time trends in the municipal mortality rates for two time periods.

After estimating the fixed coefficients for the spline terms, the statistical significance of each random coefficient was evaluated. Inclusion or exclusion of a random coefficient was decided according to the result of the goodness-of-fit test, as described below. After introducing all the significant random coefficients, their covariances were tested individually in order to obtain a more parsimonious model.

In the third stage, the indicator variables for the country's regions were introduced into the model to explain the intercept's variability, which in this case is the predicted value of the rates' log at baseline (1995). Finally, an analysis of interaction was performed as an attempt to explain the variability between the longitudinal patterns in the municipalities' mortality rates. At each step, the statistical significance of the interactions between one term of the spline and the indicator variables of the regions was tested.

The statistical significance of including fixed or random coefficients in the model was always accompanied by a standard statistical procedure. In the case of random coefficients, the goodnessof-fit test was applied 15,16. This procedure uses the value of minus twice the log of the fitted model's goodness-of-fit, expressed here as -21 17 . More specifically, the test's statistic is the difference between the $-2 \mathrm{l}$ values of the fitted models under study. The size of this difference must be compared to the critical values in the chi-square distribution, whose number of degrees of freedom is equal to the number of parameters in the general model that are not estimated in the reduced model. Large values for this difference indicate the significance of random effects. The significance of each fixed effect (coefficient) was evaluated by the t test or Wald test.

\section{Results}

Figure 1 shows the distribution of the log mortality rates, clearly indicating normality.

Table 2 presents the results of the fit for the multilevel model, used for the data analysis.

The first column shows the variables and their respective fixed effects, comprising the four models, in addition to the variances and covariances of the significant random effects in the second modeling stage. The other columns show the results of the other stages, except for the empty model. This model shows an ICC of 0.43 , i.e., $43 \%$ of the total variance was due to the variability between municipalities, while the rest was due to temporal fluctuations in the mortality rates. The insertion of variables related to time or municipalities can substantially modify this value. By performing the calculation after the last stage, for example, the ICC was equal to 0.61, i.e., in the final model the second level accounted for $61 \%$ of the total variance. The increase in the ICC was due to the fact that when one inserts first or second-level explanatory variables, the respective unexplained variances decrease. And in this scenario the regions increased the second level's weight in the model's total variance.

In the analysis of the longitudinal trend (second stage of the analytical strategy), the fixed and random coefficients of the cubic spline terms with a node in 1995 were evaluated statistically. All the terms had highly significant fixed effects (see Table 2, first column, first section), while only the random coefficient of the cubic term to the left of the spline was not significant (difference in the -2 l function $=1.076$, with 3 degrees of freedom). Meanwhile, the coefficient of the righthand cubic term was highly significant (difference in the -2 l function $=25.506$, with 3 degrees of freedom), showing more heterogeneity in the mortality rate time trends for 1996-2000 than for 1990-1995. Figure 2 shows the rates predicted by the model on a log scale, after adjusting the spline with random coefficients.

The next step in the analysis was to verify whether the regions to which the municipalities belong would explain the baseline variability in the mortality rates (1995), taking the Southeast Region as the reference. As a result, the North and Northeast had substantially higher (and highly significant) mortality rates as compared to the 


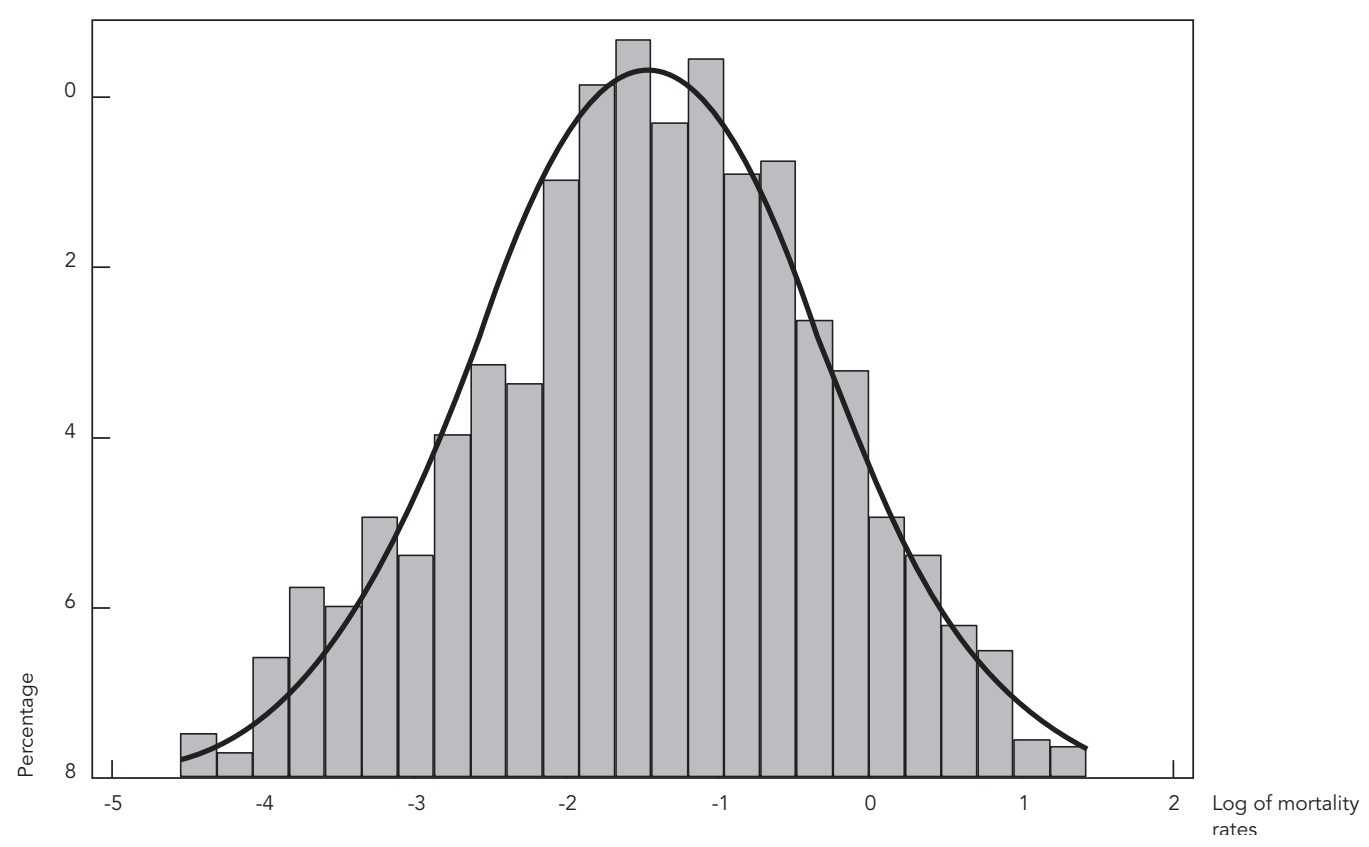

Southeast Region (see Table 2, second column, second section). Figure 3 shows the model's predicted rates by region, according to the third modeling stage and on a log scale.

The last column in Table 2 shows the results of the last modeling stage. All the sets of interactions between one spline term and the indicator variables for the regions were tested, but only the one for the linear term was statistically significant. As for the mean mortality rates by region in 1995, the differences observed in the previous model's fit between the Southeast and North/Northeast remained significant (Table 2, third column, second section). The mean mortality rate for the 122 municipalities decreased significantly, as observed in the linear spline term $(-0.190)$ in relation to the reference region (Southeast). A statistically significant difference was observed in the downward trend in the mortality rates in the Northeast $(-0.190+0.067)$ and Central-West $(-0.190+0.095)$ as compared to the Southeast. Figure $3 \mathrm{~b}$ graphically depicts the rates predicted by this model. The decrease in the rate was sharper in the North and slightly slower in the South as compared to the Southeast, but these differences were not statistically significant. Im- portantly, inclusion of these cross-interactions produced slight changes in the coefficients for the regional variables as compared to the previous model, but the statistical significance was maintained.

The curves shown in Figures $3 a$ and $3 b$ show different patterns in the decreases in mortality rates. Obviously, the model for the final stage, based on which the predictions shown in Figure $3 \mathrm{~b}$ were calculated, had a better fit than the model for the previous step, and was thus preferable. However, it is interesting to compare the sets of predictions according to the two models. Initially, the intercepts pertaining to the regions remained practically unchanged. However, large differences occurred at the beginning of the period between the rates predicted by the model (on the log scale) for the North, Northeast, and Central-West. The last model's fit further shows that the mean decrease in the rates in the North was similar to that of the Southeast and South, differing significantly from the Northeast and Central-West.

Finally, the indicator variables for the regions were able to partially explain the variability between the time trends in the municipalities, in re- 
Mortality rate from infectious diarrhea in children under five years, according to Region of Brazil, 1990-2000.

\begin{tabular}{|c|c|c|c|}
\hline & Time trend & $\begin{array}{l}\text { Time trend with } \\
\text { effects of regions }\end{array}$ & $\begin{array}{l}\text { Time trend with effects of regions } \\
\text { and interactions }\end{array}$ \\
\hline \multicolumn{4}{|l|}{ Fixed effects (1st level) } \\
\hline Constant & $-1.27576(0.08363)$ * & $-1.51867(0.08716)$ & $-1.48578(0.08763)$ * \\
\hline Linear & $-0.17046(0.01625)$ * & $-0.17047(0.01621)$ & $-0.19032(0.01736)$ * \\
\hline Quadratic & $-0.05674(0.01165)$ * & $-0.05674(0.01165)$ & $-0.05677(0.01165)$ * \\
\hline Cubic to left & $-0.00921(0.00231)$ * & $-0.00920(0.00231)$ & $-0.00923(0.00231)$ * \\
\hline Cubic to right & $0.00943(0.00237)$ * & $0.00943(0.00237)$ & $0.00943(0.00237)$ * \\
\hline \multicolumn{4}{|l|}{ Fixed effects (2nd level) } \\
\hline North & - & $1.43207(0.36610)$ * & $1.49077(0.37454)$ * \\
\hline Northeast & - & $1.21182(0.15744)$ * & $1.10088(0.16109)$ * \\
\hline South & - & $-0.04445(0.14688)$ & $-0.09365(0.15029)$ \\
\hline Central-West & - & $0.43436(0.28744)$ & $0.27564(0.29407)$ \\
\hline \multicolumn{4}{|l|}{ Cross-interactions } \\
\hline Year-centered/ North & - & - & $-0.03651(0.04779)$ \\
\hline Year-centered/ Northeast & - & - & $0.06738(0.02058)$ * \\
\hline Year-centered/ South & - & - & $0.02977(0.01920)$ \\
\hline Year-centered/ Central-West & - & - & $0.09534(0.03753)$ * \\
\hline \multicolumn{4}{|l|}{ Random effects } \\
\hline Constant & $0.72669(0.10212)$ & $0.51383(0.07487)$ & $0.51024(0.07447)$ \\
\hline Linear & $0.01187(0.00399)$ & $0.01173(0.00389)$ & $0.01153(0.00387)$ \\
\hline Quadratic & $0.00087(0.00031)$ & $0.00089(0.00031)$ & $0.00087(0.00030)$ \\
\hline Cubic to right & $0.00004(0.00003)$ & $0.00004(0.00003)$ & $0.00003(0.00003)$ \\
\hline Constant-Linear & - 0.01029 (0.00709) & $-0.01875(0.00625)$ & $-0.01732(0.00591)$ \\
\hline Constant-Quadratic & - $0.00798(0.00241)$ & $-0.00761(0.00212)$ & $-0.00753(0.00211)$ \\
\hline Linear-Quadratic & $0.00239(0.00099)$ & $0.00238(0.00096)$ & $0.00244(0.00096)$ \\
\hline Linear-Cubic to right & $-0.00056(0.00033)$ & $-0.00055(0.00032)$ & $-0.00058(0.00033)$ \\
\hline Quadratic-Cubic to right & $-0.00015(0.00009)$ & $-0.00015(0.00009)$ & $-0.00015(0.00009)$ \\
\hline
\end{tabular}

Note: Year-centered refers to the variable "year" centered on 1995

* Fixed effects with statistical significance.

lation to the linear spline term, but the same was not true for the quadratic term and the right-hand cubic term. The values found for the differences in the -2l function were $3.33(p=0.50)$ for the quadratic term and $4.01(p=0.40)$ for the cubic term. The relative variability of the other spline terms could be explained by other factors related to the municipalities, so other studies would be helpful for identifying the most relevant factors.

\section{Discussion and conclusion}

Determination of the health-disease process has fueled a longstanding debate in epidemiology. In the past, the causes of diseases were identified with magical factors and vapors emanating from swamps. Beginning in the $19^{\text {th }}$ century, microbiology began its process of consolidation, establish- ing the role of microorganisms in this process 18 The latter half of the 20th century witnessed increasing acceptance of the notion that illness is related to individual position in the social context ${ }^{19}$. The diseases studied in the current study provide a good example of this concept, since they clearly occur more frequently in less developed regions.

The World Health Organization (WHO) focuses special attention on research and monitoring of infectious diarrheic diseases. The rates are high in impoverished areas of the planet. Analysis of deaths from these diseases further highlights their social determinants.

In recent decades, the implementation of health program-related actions, especially oral rehydratation therapy, have succeeded in decreasing the number of cases and death. This success could lead to erroneous conclusions concerning 


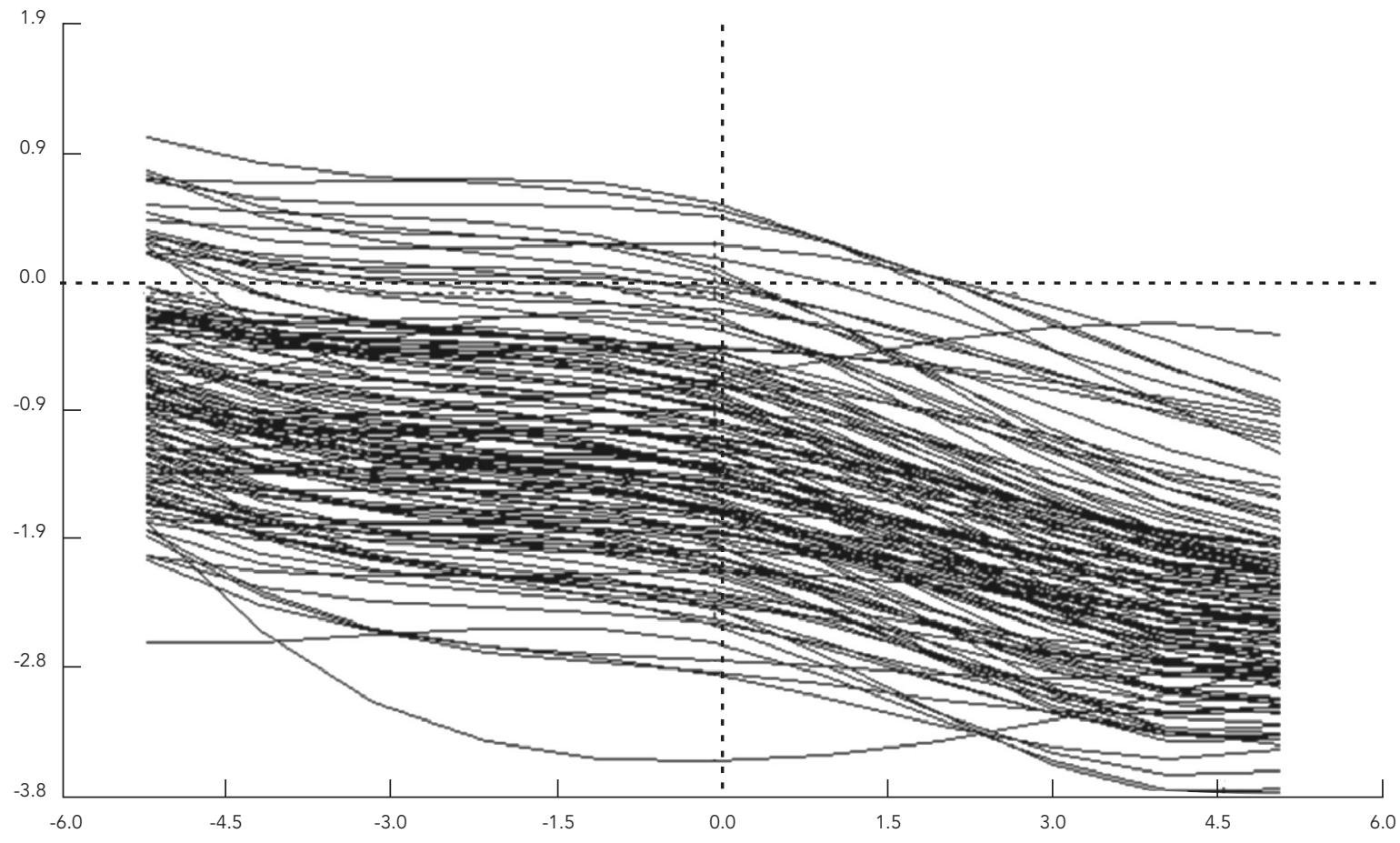

Source: Mortality Information System (SIM), Information Technology Department, Unified National Health System (DATASUS; http://www.datasus.gov.br).

the avoidability of the deaths that still occur. Are they in fact more difficult to avoid?

Analysis of mortality data for infectious diarrheic diseases in under-five children allows investigating some interesting questions. First, the target age bracket accounts for $80 \%$ of the deaths, and within this group nearly all of the deaths occur from 6 months to two years of age. Second, in this age bracket, the mobility of individuals is very small, limited to the household and peridomicile, thus emphasizing the prevailing living conditions as a preponderant factor in the occurrence of these diseases. In addition, any factor that increases individual vulnerability, such as measles (which can also be considered a socially determined event), greatly increases the risk of illness and death from infectious diarrheic diseases.

The results shown here unequivocally answer the questions posed at the end of the introduction. There is a statistically significant variability between the municipalities, partially explained by the regions, highlighting the North and Northeast, which showed significantly higher rates than the Southeast. A downward time trend was also observed, with the regions also partially explaining the differences in the decreases in rates between the municipalities.

The mortality rate distribution (Table 1) is consistent with that found in other countries, considering criteria related to degree of development 20. The rates are highest in the regions with the lowest municipal Human Development Index.

The results shown in Table 2 and the differences between the left-hand curves in Figure 2 show that the regions exert a significant effect on mortality, emphasizing the fact that there is a significant difference between the regions, at a time when the values predicted for the log rate appear to tend towards stabilization. As shown in Figure 1 , it is possible to identify municipalities with higher predicted log rates, which may also reflect internally differentiated stages of development.

The recognition that the occurrence of infectious diarrheic diseases is related to social inequality has consequences for identifying public policies to control them. The so-called "regional 
Figure 3

Predicted log of mortality rates from infectious diarrheic diseases in children under five years, according to Region of Brazil, 1990-2000. The graph on the left (3a) corresponds to the random intercept model, and the graph on the right (3b) to the random intercept/random slope model.

3a) Random intercept model

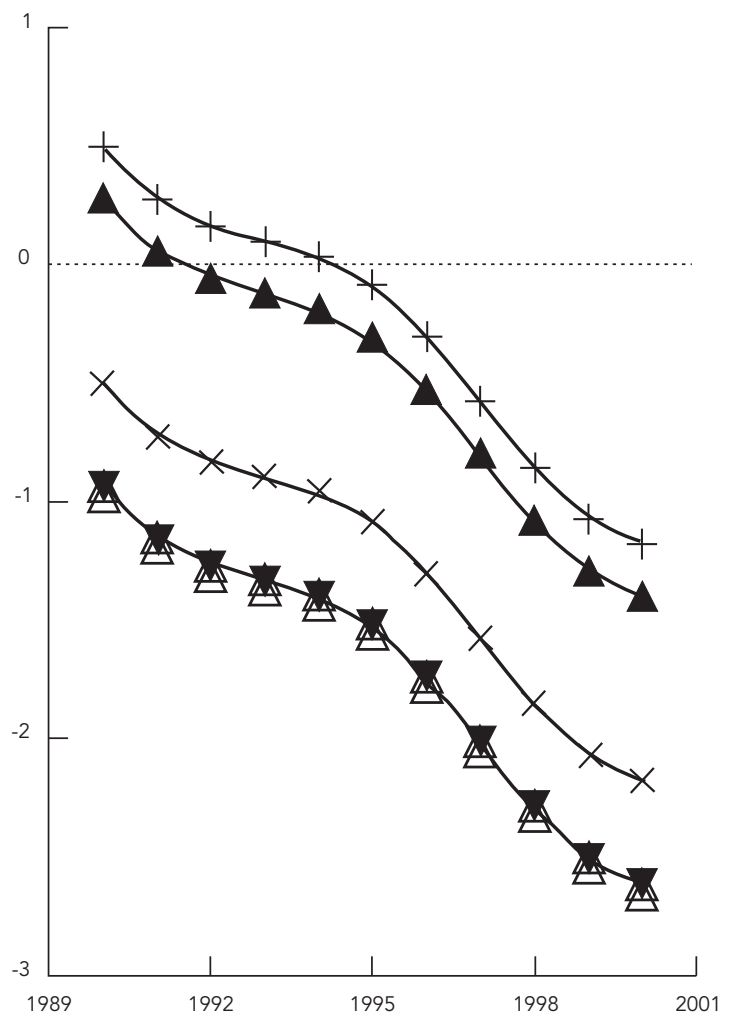

3b) Random intercept/Random slope model

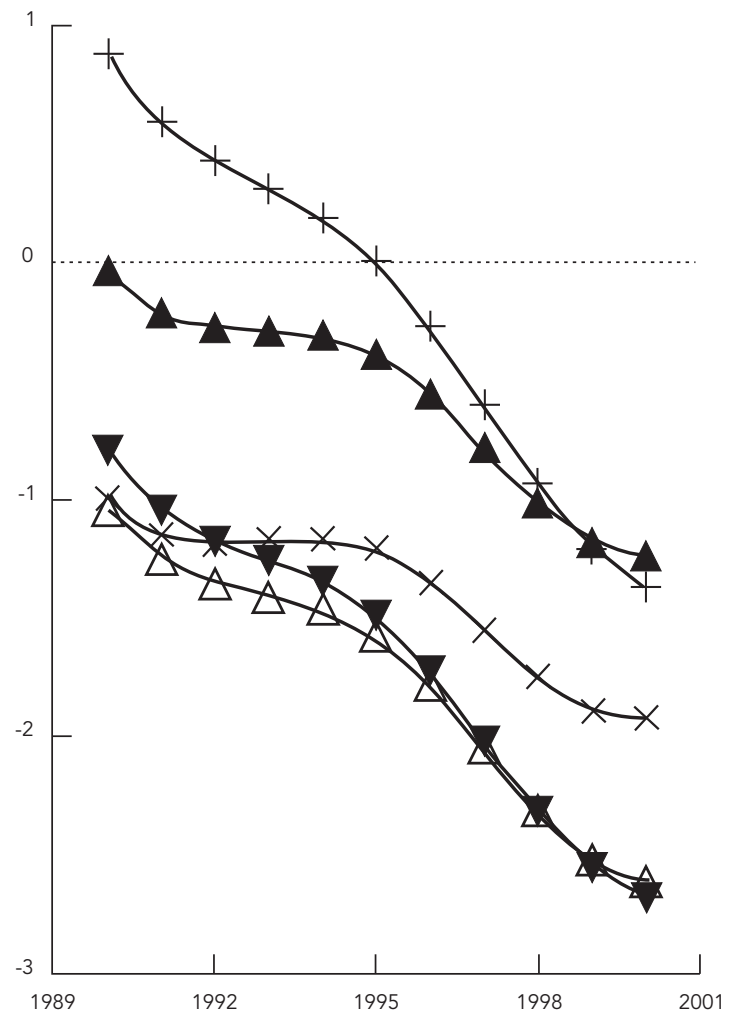

Legend: + North; $\boldsymbol{\Delta}$ Northeast; $\times$ Central-West; $\boldsymbol{\nabla}$ Southeast; $\Delta$ South

effect" calls for more in-depth epidemiological research to identify factors that differentiate the regions and determine mortality trends for these diseases. In principle, knowledge of the transmission mechanisms and risk factors can identify measures that need to be implemented. The risk factors for diarrheic diseases indicate the measures to be implemented for their control. Such measures can be related to socioeconomic conditions and are independent of knowledge concerning the occurrence of cases and deaths from these diseases in a given region, since lack of such knowledge may be the result of the absence or insufficiency of local information systems.

Fecal-oral transmission of infectious diarrheic diseases suggests a set of measures capable of controlling them, such as: access to clean drinking water, sewage treatment, proper food handling, personal hygiene, and vector control. Still, some questions need to be answered when implementing public policies for such control. What is the expected impact of each measure? What is the strength of interaction between these measures? Why do identical measures produce different results when comparing municipalities and regions?

The answers to these questions are not always easy to obtain. Inadequate research can lead to mistaken diagnoses and thus to ineffective measures and waste of public resources. The research and data analysis methods for these diseases need to be improved. Since these events involve auto-correlated outcomes organized in a hierarchical structure, multilevel models prove quite promising, although their use in the health field is recent. 
Another major contribution by these models is that they allow working with a large number of units at different hierarchical levels, presenting an overall trend, while succeeding in presenting individualized results for each unit at the end of the model's fit. Taking the current study as an example, after presenting overall and region-byregion trends, it is possible to individualize the results for each of the 122 municipalities and compare them to results from other units from the same level or from a higher level of aggregation.

As for the choice of the mathematical model, besides displaying the data organization in a hierarchical structure, multilevel models also enjoy the following advantages 5,17,21: (1) greater precision in estimating regression coefficients and their variances; (2) flexibility in modeling the data variance structure as a function of explanatory variables, when the data variance is non-homogeneous.
The data analyzed in the current study show an important decrease in mortality from diarrheic diseases, with a predicted stabilization of the rates well below those observed in the last decades. However, it is important to recall that we are dealing with diseases that are classified as having "avoidable causes". The health system can help further improve the morbidity and mortality indicators. This contribution can occur at different levels, like the implementation of measures to eliminate risk factors, improvement in the epidemiological surveillance of diarrheic diseases, enhanced research methods, and improved capacity by health services to correctly diagnose and treat cases. However, the main quality leap will come through improvement in socioeconomic indicators and a decrease in regional inequalities. The improvement in these indicators will further reduce or even eliminate these deaths, as observed in 89 points in the historical series analyzed above.

\section{Resumo}

Neste estudo, analisou-se a mortalidade por doenças diarréicas de origem infecciosa em menores de cinco anos, em municípios brasileiros com mais de 150 mil habitantes, exceto capitais. Realizou-se uma análise longitudinal, utilizando um modelo multinível para as taxas anuais de mortalidade de 1990 a 2000, estando as medidas no tempo no primeiro nível e municípios no segundo. Considerou-se como variável dependente o logaritmo natural da taxa de mortalidade e como variáveis independentes os termos relativos à tendência temporal e às regiões do país. Tomou-se o ano de 1995 como linha de base da série histórica, modelando-se as séries à sua esquerda e à sua direita.
De 1990 a 1995, houve queda importante nas taxas, ao passo que de 1995 a 2000 as taxas caíram de forma mais heterogênea. No modelo de intercepto aleatório e tendência linear fixa verifica-se que as regiões Norte e Nordeste têm taxas, previstas pelo modelo, mais altas (em 1995) do que o Sudeste. Entretanto, analisando todo o período, detectou-se uma diferença estatisticamente significativa, não só nos interceptos, mas também no padrão linear de queda das taxas, segundo as regiões do país.

Diarréia; Mortalidade Infantil; Bem-Estar da Criança 


\section{Contributors}

J. V. Sergio participated in the study design, literature review, analysis of the results, and writing of the final article. A. C. Ponce de Leon contributed to the elaboration of the methodology, analysis of the results, and writing of the final article.

\section{References}

1. World Health Organization. Medical education: teaching medical students about diarrhoeal diseases. Geneva: World Health Organization; 1999.

2. Jawetz E, Brooks G, Butel JS, Ornston LN, Melnick JL, Adelberg EA. Medical Microbiology. 22nd Ed. East Norwalk: Appleton \& Lange; 1995.

3. Gerolomo M. A sétima pandemia de cólera no Brasil, sua evolução e fatores relacionados a sua implantação e disseminação [Masters Thesis]. Rio de Janeiro: Instituto de Medicina Social, Universidade do Estado do Rio de Janeiro; 1997.

4. Instituto de Pesquisa Econômica Aplicada. Novo atlas de desenvolvimento humano no Brasil, 2002. Brasília: Instituto de Pesquisa Econômica Aplicada; 2002.

5. Barros AJ, Hirakata VN. Alternatives for logistic regression in cross-sectional studies: an empirical comparison of models that directly estimate the prevalence ratio. BMC Med Res Methodol 2003; 3:21.

6. Diggle PJ, Liang K, Zeger SL. Analysis of longitudinal data. Oxford: Claredon Press; 1994.

7. Goldstein H. Multilevel statistical analysis. 2nd Ed. London: Kendall's Library of Statistics; 1995.

8. Sergio JV. Uso de categorias da Classificação Internacional de Doenças como indicador de utilização de serviços de saúde. Cad Saúde Colet (Rio J) 1997; (5):139-44.

9. Almeida Filho N. Rouquayrol MZ. Introdução à epidemiologia moderna. Salvador: Editora Apce/ Rio de Janeiro: ABRASCO; 1990.

10. Organização Mundial da Saúde. Manual da classificação estatística internacional de doenças, lesões e causas de óbitos - nona conferência de revisão. São Paulo: Centro Brasileiro de Classificação de Doenças em Português; 1985.

11. Organização Mundial da Saúde. Classificação estatística internacional de doenças e problemas relacionados à saúde, 10a revisão. São Paulo: Centro Colaborador da OMS para a Classificação de Doenças em Português; 1995.

\section{Acknowledgments}

The authors wish to thank Diana Maul de Carvalho and Paulo Maurício Lourenço Campaña for collaborating in the final revision of the manuscript.
12. Rodríguez G, Goldman N. An assessment of estimation procedures for multilevel models with binary response. J R Stat Soc [Ser A] 1995; 158(Pt 1):73-89.

13. Goldstein H, Rasbash J. Improved approximations for multilevel models with binary responses. J R Stat Soc [Ser A] 1996; 159(Pt 3):505-13.

14. Snijders T, Bosker R. Multilevel analysis: an introduction to basic and advanced multilevel modeling. London: Sage Publications; 1999.

15. Browne W, Draper D. A comparison of Bayesian and likelihood-based methods for fitting multilevel models. http://multilevel.ioe.ac.uk/team/mate rials/wbrssa.pdf (accessed on 17/Oct/2007)

16. Hox JJ. Applied Multilevel Analysis. Amsterdam: TT-Publikaties; 1995.

17. Ferrão MA, Leite IC, Beltrão KI. Modelagem multinível em avaliação educacional. Rio de Janeiro: Instituto Brasileiro de Geografia e Estatística 2001.

18. Barata RCB. A historicidade do conceito de causa. In: Carvalheiro JR, organizador. Epidemiologia: textos de apoio. Rio de Janeiro: ABRASCO; 1985. p. 13-27.

19. Laurell AC. A saúde-doença como processo social. In: Nunes ED, organizadores. Medicina social: aspectos históricos e teóricos. São Paulo: Global Editora; 1983. p. 133-58.

20. World Heath Organization. Water quality. Guidelines, standards and health: assessment of risk and risk management for water-related infectious disease. Geneva: World Health Organization; 2001.

21. Bryk AS, Raidenbush SW. Hierarchical linear models for social and behavioral research: applications and data analysis methods. Newbury Park: Sage Publications; 1992.

Submitted on $15 / \operatorname{Jan} / 2007$

Final version resubmitted on $01 / \mathrm{Nov} / 2007$

Approved on 22/Jan/2008 